\section{Providing Social Support for Underrepresented Racial and Ethnic Minority PhD Students in the Biomedical Sciences: A Career Coaching Model}

\author{
Simon N. Williams, ${ }^{\text {t* }}$ Bhoomi K. Thakore, ${ }^{\S}$ and Richard McGee ${ }^{\| *}$ \\ 'School of Languages and Social Sciences, Aston University, Birmingham B4 7ET, UK; ”Department \\ of Medical Social Sciences, Northwestern University, Chicago, IL 60611; `Department of Sociology, \\ Elmhurst College, Elmhurst, IL 60126; "Feinberg School of Medicine, Northwestern University, \\ Chicago, IL 60611
}

\begin{abstract}
Improvement in the proportion of underrepresented racial and ethnic minorities (URMs) in academic positions has been unsatisfactory. Although this is a complex problem, one key issue is that graduate students often rely on research mentors for career-related support, the effectiveness of which can be variable. We present results from a novel academic career "coaching" intervention, one aim of which was to provide supplementary social support for PhD students, particularly those from underrepresented backgrounds. Coaching was delivered both within small groups and on an individual basis, with a diverse group of coaches and students coming from many universities. Coaches were provided with additional diversity training. Ninety-six semistructured interviews with 33 URM students over 3 years were analyzed using a qualitative framework approach. For most of the URM PhD students, coaching provided social support in the form of emotional, informational, and appraisal support. Coaching groups provided a noncompetitive environment and "community of support" within which students were able to learn from one another's experiences and discuss negative and stressful experiences related to their graduate school, lab, or career plans. This coached peer group model is capable of providing the social support that many URM students do not find at their home universities.
\end{abstract}

\section{INTRODUCTION}

Improving the proportion of underrepresented racial and ethnic minorities (hereafter URMs) in academic positions across the life sciences is a priority for research on interventions (Fagen and Labov, 2007; National Academy of Sciences [NAS], 2011; National institutes of Health [NIH], 2012; Gibbs et al., 2014). The PhD is a key juncture that determines whether URMs are likely to persist toward a faculty career. Critical to graduate students' success is whether they receive adequate support from their mentors and peers (Byars-Winston et al., 2010; McGee et al., 2012; Gibbs and Griffin, 2013). Although a number of initiatives (e.g., Postbaccalaureate Research Education Program, or PREP) are providing academic and professional preparation for some URM students before graduate school (e.g., Gazley et al., 2014; Remich et al., 2016), graduate students either often lack structured programs and/or rely on research mentors for career-related guidance and encouragement during the PhD (Gibbs and Griffin, 2013; McGee et al., 2012; McGee, 2016). The social support that graduate students, and URM graduate students in particular, receive can be highly variable (McGee et al., 2012; Thakore et al., 2014). There may be a number of reasons why URM students often lack adequate support from mentors, such as students' lack of confidence in reaching out to mentors, or mentors focusing only on those students deemed "rising stars" according to conventional metrics (like grade point average or prestige of undergraduate university; Bangera and Brownell, 2014). Recent initiatives have sought to
Rebecca Price, Monitoring Editor

Submitted January 30, 2017; Revised September 7, 2017; Accepted September 11, 2017

CBE Life Sci Educ December 1, 2017 16:ar64 DOI:10.1187/cbe.17-01-0021

*Address correspondence to: Richard McGee (r-mcgeeanorthwestern.edu).

(c) 2017 S. N. Williams et al. CBE-Life Sciences Education (c) 2017 The American Society for Cell Biology. This article is distributed by The American Society for Cell Biology under license from the author(s). It is available to the public under an Attribution-Noncommercial-Share Alike 3.0 Unported Creative Commons License (http:// creativecommons.org/licenses/by-nc-sa/3.0). "ASCB ${ }^{\circledR "}$ and "The American Society for Cell Biology ${ }^{\circledR "}$ are registered trademarks of The American Society for Cell Biology. 
extend mentors' training to include professional development competencies (Handelsman et al., 2005; Pfund et al., 2013, 2014; Prunuske et al., 2016). However, the fact that there has been little improvement in the proportion of URMs in faculty positions over the past few decades suggests a need for supplemental career support beyond what many mentors are equipped to provide due to a lack of time or training (McGee et al., 2012; Thakore et al., 2014; Williams et al., 2016a). Additionally, the culture of science can create a competitive or academically intimidating environment that can sometimes lead to a lack of supportive peer networks (Hurtado et al., 2009), and URM students may also experience added stress as a result of race- or ethnicity-related marginalization or isolation (Tinto, 1993; Cole and Barber, 2003; Hurtado et al., 2009; Trujillo and Tanner, 2014), which may deter them from persisting toward an academic science career (NAS, 2011; Gibbs and Griffin, 2013; Williams et al., 2016a).

In this paper, we draw on findings from a novel "coaching" model to explore the potential value of supplementary social support for URM PhD students in the biomedical sciences. In previous research, we have shown how coaches were seen as a source of vicarious learning (observational learning) for many URM students (Williams et al., 2016b). We found that coaches were often seen as career role models, particularly for those students who shared a racial or ethnic background with their coaches, or for those who had few conversations about career-related topics, or for those who desired a different type of academic career than those chosen by their principal investigators (PIs) or research mentors (Williams et al., 2016b). In this paper, we add to our previous analysis by focusing on the influence of both coaches and coaching group peers. We also move from a narrow focus on career-related vicarious guidance, to a broader focus on social support. Although a broad concept with a vast literature, social support is a useful heuristic lens to explore whether URM students benefited not just from hearing about more senior scientists' (including URM scientists) success stories and the ways they overcame challenges and barriers, but also whether coaches and peers were resources of emotional encouragement and reassurance and enablers of more accurate self-assessment and reflection.

Coaches differ from traditional research mentors in a number of ways. A fuller description of the coaching model can be found in the Methods section and in our study protocol (Thakore et al., 2014). Briefly, our coaching model involved establishing small "coaching groups" in which a diverse mix of students of different races, ethnicities, genders, institutions, and scientific disciplines were guided by a faculty coach (from a different institution than the students). Coaching groups met annually in person and virtually between these meetings. Coaching group discussions focused minimally on scientific topics, but primarily on issues related to career planning and professional development, as well as on issues related to diversity, discrimination, and "being different" in science. Thus, it was anticipated that creating such a diverse and largely noncompetitive space for discussion would provide students with social support to supplement the support they may or may not have received in their home institutions.

\section{THEORETICAL FRAMEWORK: SOCIAL SUPPORT}

Research has shown how social support is an important means through which stress is "buffered" in occupational settings
(LaRocco et al., 1980; House, 1981; House et al., 1988; Glanz et al., 2002). Building on J. S. House's typology, we take social support to encompass emotional support, informational support, appraisal support, and instrumental support (House, 1981; Glanz et al., 2002). Emotional support includes listening to others' concerns, or sharing common life experiences and is characterized by expressions of empathy, trust, and caring (House, 1981), as well as feeling valued and a sense of "belonging" (Langford et al., 1997). Informational support comes in the form of advice and guidance and the provision of instructional or other informational resource, particularly useful in solving problems and in times of stress (Langford et al., 1997; House, 1981). Appraisal support involves the provision of constructive and honest feedback, as a means of self-assessment and social comparison (House, 1981) and the validation of one's experience and perspectives (Stewart, 1989). Finally, instrumental support involves the provision of "tangible" material goods or services, such as financial aid (House, 1981; Glanz et al., 2002).

URM students arguably have a greater need for social support because of the feelings of isolation and the negative stereotypes they experience during their studies (Syed et al., 2011; Azmitia et al., 2013). At various stages of education, social support has been seen to foster the success of URMs in STEM (science, technology, engineering, and mathematics) fields (Gloria et al., 1999; Lent et al., 2000; Syed et al., 2011; Hurtado et al., 2011; Azmitia et al., 2013). Social support can enhance motivation, foster the development of one's identity as a scientist, and facilitate a sense of belonging to a larger community of scientists (Syed et al., 2011; Azmitia et al., 2013; Gibau, 2015). For example, social support from faculty or same-race peers within the college environment can positively affect African-American and Latino students' adjustment and comfort (Cole and Espinoza, 2008).

In this qualitative study, we explore the ways in which coaches and peers can act as a source of social support (emotional, informational, and appraisal support), using experiences of our sample of URM PhD students in the biomedical sciences during the first 3 years of their $\mathrm{PhD}$ training, and how this social support helped to "buffer" some of the stresses and challenges that may arise during the early years of graduate school. In this paper, we explore whether coaching groups provided social support for students. Social support is a subjective experience related to whether or not individuals believe they have access to supportive resources. As such, we focus on perceived social support, insofar as we discuss whether the students identified coaches and peers in the intervention as sources of social support. From this perspective, the very fact that an individual perceives something or someone as being - or potentially beingsupportive is a determinant of effective coping (Dunkel-Schetter and Bennett, 1990). This includes cases wherein support is not necessarily activated, but the individual knows it is there if needed.

\section{METHODS}

This study was reviewed and approved by Northwestern University's Institutional Review Board, Project STU00035424. Participants, both students and coaches, provided informed consent. 


\section{Setting and Design}

The Academy for Future Science Faculty (hereafter the "Academy") is a novel coaching program aiming to positively influence biomedical science $\mathrm{PhD}$ students' persistence into academic careers, with a particular focus on encouraging and supporting URM students. The coaching intervention has two cohorts: cohort 1 recruited students just as they were about to start their PhDs; and cohort 2 recruited students who were approximately 18 months away from completion of their PhDs (according to their own estimates; see Figure 1 in Thakore et al., 2014). As part of a broader program of research on career coaching (Thakore et al., 2014), in this paper, we present results from a qualitative study in which we analyze social support through the perceptions of URM students in cohort 1 . The experiences of participants in cohort 2 have been explored in previous papers (Williams et al., 2016a,b). Additional details and discussion about the intervention can also be found in our study protocol (Thakore et al., 2014; see also Williams et al., 2016a,b). To explore students' perceptions of their experiences in the intervention, we have been conducting annual interviews. This study incorporates interview data over three time points-after 1, 2, and 3 years of the $\mathrm{PhD}$. Interviews were conducted during the Summers of 2012 to 2014.

\section{Participants}

In Summer 2011, 99 participants were selected to participate in cohort 1 of the Academy. Of these, 51 self-identified as URMs. Eligibility criteria for this cohort of the study were 1) enrollment in a U.S. biomedical PhD program beginning Fall 2011, 2) expressed interest in an academic career, and 3) U.S. citizenship or legal permanent residence. Random stratified sampling was used to ensure that the Academy group contained roughly equal numbers of students from each gender and from each racial/ethnic group. Students were then subdivided into 10 "coaching groups" of 10 students each. Coaching groups were also stratified to ensure that students were as balanced as possible according to race/ethnicity and gender (i.e., each group had four to six females and four to six males, including two Asian, two Black, two white, and two Hispanic students, with the remaining students, including three Native American students, randomly allocated across the groups). The decision to include Asian/Asian-American and white students in the Academy was made to purposely create a diverse community of students to promote engagement and often difficult discussions across gender, racial, and ethnic boundaries. We also began with no presumption that only URM students could benefit from coaching and as an experiment wanted to study comparisons. However, for this paper, we focus our analysis on the views of URM students, given our focus on the extent to which supplementary social support could be useful for those students who are underrepresented in science. Students were also recruited into a control group, but these students are not discussed in this paper. Additional details of the full study population of the intervention can be found in the study protocol (Thakore et al., 2014).

Coaches were recruited via advertisements for participation through program and organization lists or listservs (the Association of American Medical College's Graduate Research Education and Training [GREAT] group) and to the program directors of the Maximizing Access to Research Careers, the Research
Initiative for Scientific Enhancement, the PREP and the Lewis Stokes Alliances for Minority Participation programs. Coaches were selected on the basis of their track record of mentoring young scientists, including URM students. For this cohort, 10 coaches were selected from among faculty leaders of research training and diversity efforts in U.S. universities. Coaches included one Asian-American male, one Asian-American female, two Hispanic females, three white females, and three white males. Professionally, the coaches all were faculty as well as deans $(n=2)$, associate deans $(n=5)$, assistant deans $(n=$ $2)$, or program directors $(n=1)$ in either private $(n=6)$ or public $(n=4)$ medical schools in the United States (see Thakore et al., 2014). From the applications received, we were unable to recruit more URM coaches (including Black/African-American coaches, Hispanic male coaches, or Native American/American Indian coaches). However, for the second cohort (Academy 2) we were able to recruit a more racially diverse pool of coaches (Thakore et al., 2014). Coaches and students were not matched according to scientific discipline/field, and coaching groups were designed to ensure that coaches came from different institutions than their students and that no more than two students in any group came from the same institution. During the first 3 years of the intervention, coaches received a modest honorarium as compensation for their time. Coach training occurred during an initial 2-day meeting before the first Academy in-person meeting (discussed in The Intervention), and regularly over the first 3 years via phone conference.

As part of their selection, potential coaches were asked to submit an application that included a "personal statement" detailing why they wanted to participate in this intervention. All those selected expressed a very strong interest and passion in guiding and advising students and broadening URM participation in the biomedical sciences. Coaches worked with students both one on one and within a collective coaching group. Thus, the ability to facilitate and harness the value of the group in the form of peer support and information exchange is a critical coaching skill. We choose to describe this role to provide individual support and facilitate group support as coaching to distinguish it from research mentoring, acknowledging it does not replicate all of the elements common to athletic and some other forms of professional coaching.

One of the most novel aspects of the coaches' training was its focus on social science theories. Led by a team of sociologists, coaches were encouraged to read, and later discuss, some key social science theories and concepts that might be useful in helping them understand some of the social processes and factors that can shape (encourage or obstruct) their students' progress within academic careers. The full range of theories explored in the training is discussed elsewhere (Thakore et al., 2014), although for the purposes of this article it is important to note that these discussions included the importance of developing social support through, for example, networks and collaborations, and identifying and building a "community of support."

\section{The Intervention}

Coaching in the Academy included annual, intensive 2- or 3-day in-person meetings held in Chicago, supplemented by between-meeting distance communication. By the time of the interview conducted after 3 years in the Academy (Summer 2014), students had participated in three in-person meetings 
and had approximately 3 full years of contact with their coaches and coaching groups. The in-person meeting included presentations and discussions for the intervention group as whole and coach-facilitated activities in individual coaching groups. Presentations and guided discussion prompts included such topics as "Stereotypes, Assumptions, Bias, Difference, Diversity, Discrimination: Realities of Biomedical Research Communities" and "The Roadmap to Academic Careers" (for sample meeting agendas, see Thakore et al., 2014). Students also completed individual development plans and self-assessment documents and later discussed these in their coaching groups with their coaches and peers.

Over the 12 months following the in-person meetings, students engaged with their coaches and coaching groups via group videoconferences and email or social media. Videoconferences were conducted using Adobe Connect software, which was provided as part of the intervention, or Web-conferencing freeware such as Google Hangout, Tinychat, or Skype. Although the research team provided suggestions on how to structure these virtual group communications, flexibility was retained to enable coaches, and coaching groups were encouraged to address any issues they deemed relevant to professional and personal advancement in real time. Students interacted with coaches and peers 6.6 times per year on average, with a range of $0-28$. Topics included: strategies for choosing lab rotations, stress reduction and coping skills, how to network effectively, preparing for qualifying exams, and dealing with microaggressions.

With respect to social support, we systematically looked for both evidence of social support and instances in which coaching did not provide social support. Our analysis was guided by the question of whether and how coaching can serve as a source of social support for URM biomedical PhD students and, if so, whether it can serve to buffer some of the challenges and stresses experiences by these students during the course of the first 3 years of their PhD studies.

\section{Data Collection}

Data for this paper come from 96 interviews from 33 participants conducted over 3 years (2012-2014), most ranging between $45 \mathrm{~min}$ and 1 hour, $20 \mathrm{~min}$ (three participants were available to provide only two interviews each; Table 1). Students discussed in this paper came from Academy 1, whereas students discussed in previous papers (Williams et al., 2016a,b) came from Academy 2. Risk of attrition is highest during the early stages of doctoral study, with the median time to attrition for URM students being 24 months (Sowell et al., 2015). As

\begin{tabular}{|c|c|}
\hline Participant characteristic & $N(\%)$ \\
\hline \multicolumn{2}{|l|}{ Gender } \\
\hline Female & $18(54)$ \\
\hline Male & $15(45)$ \\
\hline \multicolumn{2}{|l|}{ Race/ethnicity } \\
\hline Black & $16(49)$ \\
\hline Hispanic & $14(42)$ \\
\hline Native American & $3(9)$ \\
\hline
\end{tabular}

such, the need for positive social support may be particularly important for URMs during the early stages of their PhD studies, and this accounts for our decision to focus on cohort 1 in this paper. Although there are a number of challenges and concerns that $\mathrm{PhD}$ students face that are encountered throughout the whole of their $\mathrm{PhD}$ work and beyond, there are some distinctive challenges and concerns for early-stage $\mathrm{PhD}$ students, such as adjusting to life as a graduate student, dealing with the stress of qualifying exams, forming effective relationships with new mentors, and integrating into new lab groups, all of which are explored in Results and Discussion.

Data in this paper refer to first interview (2012, after 1 year of the $\mathrm{PhD}$ and of the Academy); second interview (2013, after 2 years of the $\mathrm{PhD}$ and of the Academy); or third interview (2014; after 3 years of the PhD and of the Academy. Interviews were conducted via telephone by a member of the research team, all of whom had professional experience in qualitative interviewing. Students were interviewed during the summer of the 3 consecutive years. The aim of the present paper was not to explore any change over time in the students' perceptions of the intervention-such evaluation will be disseminated in the future. The aim of the present paper was instead to look at the intervention as a whole and explore whether it was seen to provide social support overall and at any point-thus data from the 3 years were pooled. Interviews followed semistructured interview guides that covered a variety of topics related to students' experiences and perspectives on graduate school and career ambitions (Thakore et al., 2014). In this paper, we focus on students' experiences in the Academy, for example, "Tell me about your relationship with your coach/coaching group?" and "Do you have a particularly memorable moment from the Academy?" Full sample interview protocols are available in Thakore et al. (2014).

\section{Data Analysis}

Audio recordings of qualitative interviews were transcribed and double-checked for accuracy. A framework approach to analysis was taken (Ritchie and Lewis, 2003; Gale et al., 2013). This is a method of analysis in which qualitative data are coded and organized according to themes and subthemes, using data matrices to aid analysis. Two authors (S.N.W. and B.K.T.) coded the analysis. Coding was performed using QSR International's NVivo 10 software. Both of these authors met regularly to discuss and consult with each other during the course of the analysis, the PI of the overall study (and third author of this paper, R.M.), and additional members of the larger research group. Overall agreement between the two coders was very high, and any discrepancies were resolved by consensus. This framework approach entailed a number of processes. All authors were familiar with the interview data, each having conducted a portion of interviews related to this study and the wider research project and having contributed to discussions and preliminary data-reduction and data-tagging exercises. We developed an analytical framework for the analysis, and two authors (S.N.W. and B.K.T.) coded a sample of transcripts. After agreeing on a final coding structure, two authors (S.N.W. and B.K.T.) then coded the remainder of the transcripts. Framework analysis can be primarily deductive or inductive, depending on the particular research question (Gale et al., 2013). The concept of social support, specifically 
TABLE 2. Number of students included in the categories emotional support, informational support, and appraisal support, divided by whether they were referring to support received from coaches or peers

\begin{tabular}{|c|c|c|}
\hline Description & Students $(N)^{\mathrm{a}}$ & Representative quote \\
\hline \multicolumn{3}{|c|}{ Emotional support } \\
\hline From coach & 19 & $\begin{array}{l}\text { "There was a time I called because I had issues with one of my rotations ... and she [the coach] was } \\
\text { there, and we talked for a long time. I was very stressed at that time. But I remember feeling very } \\
\text { relieved after I talked to her, and my mind was eased, and I could actually now look at the whole } \\
\text { thing as not such a big deal." }\end{array}$ \\
\hline From peers & 15 & $\begin{array}{l}\text { "We always root [for] each other on when one of us qualifies or one of us gets a paper published. We } \\
\text { have this constant encouragement ... for any new achievements we have going on in our lives." }\end{array}$ \\
\hline From coach & 19 & $\begin{array}{l}\text { "We had a pretty good conversation when we were talking about ... identity and race, you know he sort } \\
\text { of talked about his own experiences being head of a department and also how people unintention- } \\
\text { ally perceive other people and how that affects things like hiring processes." }\end{array}$ \\
\hline From peers & 17 & $\begin{array}{l}\text { "I think hearing from other people in my coaching group, like the issues that they have gone through } \\
\text { has helped me to identify what problems need to be solved and who to go to if that makes any } \\
\text { sense, like they've had the issue before so now I know what to look for if the issue ever comes up." }\end{array}$ \\
\hline From peers & 23 & $\begin{array}{l}\text { "When we started discussing different things that can happen during graduate school, and how to } \\
\text { handle them, that was immensely helpful, especially in my personal setting ... knowing that I'm not } \\
\text { the only one this is happening to ... that I'm not imagining things." }\end{array}$ \\
\hline
\end{tabular}

${ }^{a} \mathrm{~N}$ represents the number of students who were coded as having received a particular type of social support at least once over the course of three interviews.

the typology and characterization described by House (1981), served as the basic framework for our analysis. A data matrix was used to visualize and help discern prominent themes. At various points during coding, the research team met to discuss the themes. The themes presented below represent our most prominent themes and are exemplified with sample quotations. Pseudonyms are used to protect participants' anonymity.

\section{RESULTS}

\section{Types of Support}

Table 2 describes each of the forms of support described earlier along with its observed frequency. As can be seen, these were all relatively high frequencies being expressed at some point over the three interviews by a majority of participants. Because the main focus of this analysis was on social support for URM students that others have shown is often missing, a detailed analysis of social support for the non-URM students is not provided. However, all of these forms of social support were seen for some of those students as well. Thus, social support from a group coaching model should not be seen as something exclusively available to or of value to URM students.

\section{Emotional Support}

In our sample, both coaches and peers were seen as sources of emotional support. Students described feeling that their coaches cared about them. This was the case for both coaches who proactively reached out regularly to their students to check on their progress and coaches who simply made themselves available to the students if and when they were needed. For example, Sonia (Hispanic female, first interview) found it very reassuring that her coach was there if she needed him:
He has kind of an open-email policy, where we can email him whenever we need and he'll call us back if we want to talk to him personally ... No matter what he'll always be there for us ... I love that he is so caring.

Marcus (Black male, first interview) discussed the benefits of having a coach who actively checked up on him:

My coach... she would send me a personal message, just checking on me, just making sure everything is going okay ... and she gave me her cell phone number to call her on if I need her to talk ... she takes the time out to care.

Having someone to talk to and having access to a listening ear are also important components of emotional support (House, 1981).

Students described how coaches were able to help them deal with stressful situations over the course of graduate school. For example, Latasha (Black female, first interview) explained how talking to her coach helped her to re-perceive a stressful situation related to choosing one of her lab rotations, making her feel less stressed as a result:

There was a time I called because I had issues with one of my rotations ... and she [the coach] was there, and we talked for a long time. I was very stressed at that time. But I remember feeling very relieved after I talked to her, and my mind was eased, and I could actually now look at the whole thing as not such a big deal.

Students also discussed receiving emotional support from their peers in the Academy. In our sample, some students spoke 
of a lack of intrinsic support from peers or colleagues in their own institution: "You can feel sort of isolated or like not many people know what you are going through" (Aaron, Hispanic male, second interview). One reason for this was the lack of "constant" communities of support at the beginning of graduate school, until after lab rotations have finished and a final lab has been chosen:

Communities of support are not really built in your first years of graduate school and you're not really in a stable lab environment yet so everything is always changing, but [with the Academy] you have that constant of your coaching group.Mary-Beth, Native American female, third interview

However, because the Academy was intentionally diverse, the URM students perceived it as somewhere they could talk to and be listened to by others, including other URM students. As Alex (Hispanic male, first interview) explained,

There's very nice diversity in the Academy which is fantastic because ... I got there [to my university] and there's a bunch of white people and I feel like I have no one that I can talk to. ... [In the Academy] you hear those examples from people and how they feel like singled out as far as race goes ... They were coming into a lab with all white people and not so much that they're not friends with black people, but they feel like they're singled out, they're not really asked to hang out after lab. ... [In the Academy] we all feel like we are in this together.

For students like Alex, the Academy provided a sense of community ("we all feel like we are in this together.")

For Sonia (Hispanic female, third interview), the coaching group was "kind of like a little family" that, in part due to the fact students were not directly competing with each other (e.g., for resources in their labs or fields or recognition or promotion within their labs or fields), enabled them to positively encourage and commend each other:

We always root [for] each other on when one of us qualifies or one of us gets a paper published. We have this constant encouragement ... for any new achievements we have going on in our lives.

Some students however, did not always make use of, or "activate," potential emotional support, but nevertheless reported feeling as though they benefited from knowing that a community of support was there if it was ever needed. As Ciera (Black female, first interview) explained,

Even though I didn't communicate with my peers, I knew that I could have at any moment and they would've been open to that. So I feel like it was an extra support group that I needed at the time.

For other students, regular interaction with other students "makes me feel that I know that I'm not alone going through all this craziness" (Sonia, Hispanic female, second interview). As Desiree (Black female, third interview) explained, the emotional support she received from peers in the Academy helped to validate her concerns and cope with some of her anxieties or self-doubts:
There are times where I felt like I didn't want to be in graduate school anymore ... You're always just conscious of worrying about whether or not people are going to go back and share what you are saying to them. So I do have someone, she's also in the Academy, [and] we've reached out and talked to each other a few times ... I'll say, "This is how I'm feeling, I feel guilty, or I don't feel as excited about graduate school at this point," and she'll coach me through. She's like: "We all go through this, you know." ... I might send a text and just say, "Hey, how are you doing?" and vice-versa just to check on each other and make sure we all still have our sanity.

\section{Informational Support}

Coaches and peers were also a common source of informational support. Information on a variety of topics related to graduate school and academic careers was provided and exchanged during in-person meetings and via coaching group conference calls. As noted in the Methods section, coaching group conversations were partially structured and balanced a suggested list of discussion topics (diversity and difference, adapting to lab rotations, etc.), but groups were also given room to take the conversations into areas they felt relevant to navigating graduate school and academic career planning. Informational support is particularly useful for problem solving (House, 1981). Students discussed how coaches were useful as a source of advice on how to solve problems they were experiencing in graduate school. Alex (Hispanic male, second interview) described how his coach is "great at listening to problems and offering a pretty good solution."

One of the noteworthy problems that students discussed with their coaches was the issue of grant writing and grant application. Of particular relevance to the URM students in the Academy were those fellowships that were designed for or geared to minorities. Coaches were able to advise based on their knowledge of diversity and broadening participation initiatives. As Tamara (Black female, third interview) explained,

My coach told me about the Institutional Research and Academic Career Development Awards at the NIH. It's like a teaching and research post doc and a grant that half the students have to be female and half the students have to be underrepresented minorities as well. So that program is actually one that I'm hoping to get into because it fits exactly the type of post doc that I would love to do, and my professional goals. ... I would probably not have found out because my PI actually [had] never heard of the program, and I don't think anyone at my institution knows of the program, because they don't deal with a lot of underrepresented minorities.

The coaches' inside knowledge also extended to the issue of diversity and discrimination, as Enrique (Hispanic male, second interview) discussed,

[W]e had a pretty good conversation when we were talking about ... identity and race, you know he sort of talked about his own experiences being head of a department and also how people unintentionally perceive other people and how that affects things like hiring processes.

One of the key characteristics distinguishing coaching from traditional mentoring is that coaches receive specific and 
intensive diversity training informed by social science theory, focused on issues of "being different," and acknowledging potential isolation or discrimination. This was informed by social science literature, as well as recent evidence and debate from the science careers community, related to issues of inequality such as the concept of "unconscious bias" (Ginther et al., 2011; NIH, 2012; Bangera and Brownell, 2014). In the previous quote, Enrique discussed how his coach talked about the ways in which unconscious bias can play a role in how students and trainee scientists are perceived and how that can sometimes serve as an invisible barrier or challenge for URM students.

One of the important reasons why the Academy was perceived as being a useful source of informational support was because it provided a forum for students and coaches across different universities to more openly and comfortably share their perspectives. For many students, having "a voice that's outside, who's not connected to our department at all, and doesn't know my program director or mentor" (Desiree, Black female, third interview) was very beneficial, because this voice was free of the perceived conflicts of interest that might be associated with an internal supports from within the student's own institution. One prominent example of this during coaching group discussions was instances in which students wanted to discuss problems with the relationships with their mentors or PIs. Having an external perspective was also seen to broaden the pool of knowledge and information about, for example, fellowships or generally how to succeed in the $\mathrm{PhD}$, to which the students may not have previously had access. As Carmen (Hispanic female, first interview) said,

I do like having someone outside of where I'm at [for the $\mathrm{PhD}$ ] being there for me, if that makes sense. Because she talks to us about what's it like in other programs and what do we need to do and, fellowship opportunities and stuff that I won't get here in this closed environment.

Students also drew on one another for information. For example, Alex (Hispanic male, second interview) discussed his fellowship application with a coaching group peer who had successfully received a fellowship:

Interviewer: So have you ever turned to any other Academy students for help with a particular issue?

Alex: I talked with another guy in my group who I know got an NSF [National Science Foundation] fellowship and I asked him how he was successful and he told me exactly what he did. He explained what they were looking for, how to frame my grant and that really helped, [and] obviously I got it so I am very, very thankful for the Academy and the relationships I've built so far.

Alex was able to draw on the experience of his fellow coaching group member to help him "frame" his grant application. Although previous research has shown how coaches can be useful sources of vicarious learning (Williams et al., 2016b), here we also see that the experiences of fellow students can provide an important means for students to build competence and efficacy in regard to a specific task-in this case, grant writing.
Students also discussed how tapping into the experiences of other students helped them to identify and address some of the problems they were encountering or were likely to encounter. As Andrew (Black male, second interview) explained,

I think hearing from other people in my coaching group, like, the issues that they have gone through has helped me to identify what problems need to be solved and who to go to if that makes any sense, like, they've had the issue before so now I know what to look for if the issue ever comes up.

In this sense, some students felt better prepared for challenges that may lie ahead. Others reflected on having had the opportunity to put into practice strategies they had garnered from Academy peers (e.g., stress management):

Just hearing about what everyone else is going through kind of helped me deal with what I was going through. ...Like one kid gave his opinion on how he dealt with stress. ... As I prepare for my upcoming qualifying exams I'm integrating them [his strategies] in my preparation.-Maria, Hispanic female, second interview

\section{Appraisal Support}

Students also discussed coaches in terms of appraisal support. All of the coaches had many years' experience in some type of senior administrative or student development role (e.g., dean or associate dean; for more details, see Thakore et al., 2014), and students reported valuing coaches' feedback or assessment. As Juan (Hispanic male, third interview) explained,

I use [my coach] as a marker of how I am progressing because he's done this for a long time, he's had students of his own and he's in I guess a higher position and in administration so he has an idea of how this works, and I guess kind of his confirmation can let me know if I am coming along as a student should be in my career.

There were two main ways in which coaches were seen as useful sources of appraisal support. First, for some students, their research mentors were not particularly forthcoming with providing feedback, and so coaches filled this gap. For example, Marcus (Black male, first interview) felt that, in regard to his individual development plan and self-assessment, "I've gotten more from my Academy coach, than I have from my own school." For others, coaches were a second opinion. For example, Tamara (Black female, first interview) described a conversation with her coach that made her re-evaluate her choice of lab rotation based on what skills and strengths she wanted to develop, rather than what skills and strengths she already possessed:

I had a conversation with my coach ... about choosing labs cause I had already had in my mind who I wanted to rotate with [but] he changed my perspective in that I shouldn't just fit into their research. ... I had a skill set that was very appropriate for what they were doing ... [But] he told me that it was okay to do something that was completely different because I'm not just working for them, I'm learning from them. ... To choose a lab to learn yourself better [sic] ... and I completely switched the lab I chose. 
Students here tended to again focus on the benefits of having access to an "outside voice."

Appraisal support is beneficial as a means of validating one's experience (House, 1981). When one perceives an experience as stressful, appraisal support can potentially lead to an individual re-perceiving an event in less stressful terms, for example, if it becomes perceived as "normal." Previous research has discussed the ways in which URM students felt coaches were often able to "normalize" or "validate" students' concerns and experiences (Williams et al., 2016b). Here, we also found that, for many URM students, fellow students in the Academy were able to normalize their concerns:

In [the] Academy, they [students] will say, "Oh yeah even my school, we are required to do this or that." And I am like, "Oh, all of sudden I feel much better" ... it's not only me. ... They also, like, help me gauge myself like, "What are my strengths or am I doing as good [sic] as my peers?"-Latasha, Black female, second interview

As noted above, social comparison is an important feature of appraisal support, because constructively comparing oneself to similar others can serve to validate or affirm one's own experiences (Stewart, 1989). As Andrew (Black male, first interview) put it, "I think the shared experiences ... definitely make me feel better. Like, it's good to know that other people are stressed about the same things that I would stress out about." Being able to share stressful experiences in a noncompetitive environment served to improve students' perceptions of those situations, thereby reducing the perception of them as being stressful ("make me feel better").

For Alex (Hispanic male, third interview), conversations with Academy peers served to put into perspective ("context") his problems:

Talking with my coaching group and other Academy members, shit happens to everybody. I count my blessings, I really do. It's made me a lot more grateful for the things I have, because all of us go through hardships, and some of the hardships that other people have gone through ... gives me a fantastic context of my problems, ... It's easy to say the grass is always greener, why did I come here? Why did I choose this lab? [But] knowing what the grass is like and then in fact, it's not green, it's more like brown, makes it easier for me to look at my own circumstances and know that I actually have it pretty good [sic].

These conversations left Alex with a more realistic ("knowing what the grass is like") yet positive ("have it pretty good") attitude.

In general, students felt "more free [to] say anything, any concern" (Sophia, Hispanic female, second interview). As Darius (Black male, second interview) explained,

It's been supportive and to interact with different students going through the same thing is very beneficial. Its not complaining but you are all feeling the same kind of stress and anxiety. So, you know, it becomes normal again.

One of the particularly novel elements of the Academy was that it afforded URM students the opportunity for social com- parison to others of the same race or ethnicity. As discussed earlier, many URMs were often the only or one of the only students of their racial or ethnic groups in their departments or research group. For Darius (Black male, second interview) discussions in the Academy served to affirm the uniqueness of the African-American scientist's experience:

To talk to other African Americans that are going through the same thing that you are-since there's not very many at my institution - and to be able to hear their experiences and how they might differ from the coaching group in general was also beneficial for me.

The social affirmation that took place within the Academy also included the "personal" dimension of graduate school, including social relationships with colleagues and how to handle them. As Aaron (Hispanic male, third interview) responded,

When we started discussing different things that can happen during graduate school, and how to handle them, that was immensely helpful, especially in my personal setting ... knowing that I'm not the only one this is happening to ... that I'm not imagining things.

Being able to openly discuss and compare their problems, particularly interpersonal problems, with their PIs or others in their lab, helped students to cope during times of stress during graduate school. As Latasha (Black female, second interview) described,

In my [coaching] group ... people have the, the same issues, like, "Oh my PI did this or people in my lab are like this." ... They [the coaching group] help in coping,, like, not feeling all alone. Sometimes you can get overwhelmed and feel like, "Oh, am I the only one who is going through these problems, like, with grad school," like, maybe stressed out with school and my church people can't understand that because they're not in school.

Latasha's example shows how the Academy provided support that was beneficial, because it was external to the specific institution but not external to academia. Although many students referred to extra-academic communities of support (e.g., religious communities or social activities and organizations), those communities were not able to directly understand and empathize with the experiences of a PhD student.

For others, like Sonia (Hispanic female, second interview), hearing about other URM students succeeding helped them feel more confident that they could also succeed:

The Academy-it's shown me that there are a lot more of us out there, you know, Latinos, African Americans and minorities in general ... that are trying to go far. ... This just plain gave me a boost that I could do this.

Other stressful experiences that social comparison ameliorated included choosing lab rotations and preparing for qualifying exams. As Andrew (Black male, first interview) explained, 
I think most of my coaching group has gone through their qualifying exam or will be going through it so I think it's easier for me to talk to them about it and to know that I'm not the only one to be stressed out. ... They're going through the same things that I'm going through and so that makes me feel a lot better. It kind of reduces my level of stress at least a little bit.

Being able to talk to others who had been through the same experience served to reduce their perception of this as a stressful event.

Finally, social comparison also enabled students to re-evaluate their strengths and weaknesses, sometimes in more favorable or accurate terms. In the first in-person meeting, students were asked to complete a self-assessment form (Thakore et al., 2014). This required the students to reflect on their strengths and weaknesses in relation to their peers across a number of domains, such as scientific thinking skills, scientific design skill, interpersonal skills, and coping and stress-reduction skills. In coaching groups, students were encouraged to discuss one another's strengths and weaknesses, with a view to providing constructive feedback or reflection. Coaches and coaching groups were then encouraged to refer back to these documents and discussions at various points during their conference calls. Data suggest that some students, particularly those who may not have had extensive academic or social networks before joining the Academy, sometimes had exaggerated or unrealistic expectations of what their peers had achieved. As Aaron (Hispanic male, first interview) described,

I think [of] myself like a timid person, so I don't tend to put myself out there [and] talk to people very easily. ... Before I came to the Academy, I thought about myself like I might be lower in [scientific] thinking, knowing that a lot of other people have published data going into grad school. ... [However,] when I started at the Academy, I learned that other people don't necessarily have published papers, but they're still very good thinkers and very good scientists and so that really helped me [see] maybe that my scientific thinking isn't a weakness.

This feeling of being "behind," based on unrealistic expectations, can often adversely affected students' confidence or "self-efficacy" (Williams et al., 2016b). In Aaron's case, talking with other students in the relatively noncompetitive environment of the Academy allowed him to challenge his own perceptions of being below average ("lower") in his scientific-thinking skills.

\section{Social Support from Coaches or Coaching Group Peers Was Not Always Perceived as Needed}

Although, the Academy overall can be seen to provide social support for many of the URM PhD students in our sample, there were a few instances in which students did not perceive or report a need for social support. These students tended to speak of having supportive mentors, PIs, or other colleagues. As Carl (Hispanic male, second interview) explained, "I just don't think I really needed to like seek any help outside of my PI or any of the other people I collaborated with closely." These students' views were different from those students who, as discussed earlier, did not make use of (activate) the support that the Academy made available but were still aware of it as a potential source of support if needed. In these cases, students failed to refer to their coaches as a potential source of social support.

\section{Social Support from Coaches or Coaching Group Peers Was Not Always Perceived as Accessible or Available}

There were a small number of instances in which students felt that social support was either not available or accessible to them. This tended to be because they, or their coaches or coaching group peers, were too busy to engage with the Academy or because they generally felt they did not get much out of the Academy.

Some students noted how they were unable to "find the time" (Troy, Black male, third interview) to reach out to their coaches or to participate in coaching group videoconference calls between annual in-person meetings. Maricela (Hispanic female, first interview), for example, described being too busy to reach out to her coach as well as having the impression that her coach was busy:

I just don't have the time, and I'm sure she [the coach] is super-busy, and I think the difficulty is just the time. ... I've only emailed her, like, two or three times this year and I haven't spoken to her on the phone. So I'm going to try to reconnect with her more ... I feel like I was also very busy that so I didn't make the effort to really make time to talk to her.

One major logistical difficulty that some coaching groups experienced was trying to ensure that all 10 students and the coach were able to meet via a videoconference at the same time. This was particularly difficult considering group members were usually spread across different U.S. time zones, as Jesus (Hispanic male, first interview) explained,

The reason why we didn't have enough contact is because you just get more busy with school. ... Different people have different schedules and it was really hard to get a time so that everyone would meet.

For some students, even though they engaged with their Academy coaches and coaching groups, they did not feel they received much out of the interactions. As Henry (Black male, first interview) described,

I don't get much out of group calls and we actually haven't had that many this year. ... We do emails from time to time but not even everyone replies so, it's kind of disappointing that some people don't reply at all.

These perspectives were largely held among those students in coaching groups that met less frequently (fewer than three times per year). In those groups, students also discussed their disappointment with the lack of engagement by their group peers.

\section{DISCUSSION}

In this study, we found that academic career coaching can serve as a useful source of social support for many underrepresented racial and ethnic minority graduate students in the biomedical sciences. In the Academy, experienced and specially trained 
academic coaches worked with diverse groups of $\mathrm{PhD}$ students from a range of institutions and scientific fields. Coaching groups served as a novel and noncompetitive environment, and coaches provided guidance and support that was perceived by students as being independent from their own institutions. Previous analysis focused on the role of the coach, and found, among other things, that this source of external advice and guidance is particularly beneficial in cases in which internal support (from the students' PIs or mentors in their home universities) was lacking or their relationships with their PIs or mentors were poor (Williams et al., 2016b). In this study, we have also focused on the role of peers-also a crucial component of this coaching model. We have also found that URM students, particularly in the transition to graduate school, may lack supportive resources and communities. In these instances, students in the Academy and their coaching groups offered a useful and necessary alternative support outlet. Overall, we found that, for many students, coaching was a source of emotional, informational or appraisal support.

In terms of emotional support, students emphasized how they felt cared about by coaches, who also provided a listening ear. Fellow students also provided emotional support via a sense of community. Research has shown importance of social belonging for URM students' academic and health outcomes in university (Hurtado and Carter, 1997; Walton and Cohen, 2011; Trujillo and Tanner, 2014). Most recently, Gibbs et al. (2015) found that URM postdocs, especially URM female postdocs, were less likely than well-represented students to report feeling like they "belonged" to their graduate school department and with their research group communities. The Academy was not designed to be a substitute for the social communities of graduate school research groups and departments, and efforts should continue to foster a greater sense of belonging for URM students in these communities. However, our data suggest that, in instances in which graduate school research groups or departments have failed to provide a sense of belonging for URM students, coaching groups consisting of students from different institutions and departments were able to provide alternative communities of support within which students could meet other graduate students, including other URM students.

In terms of informational support, coaches provided both inside knowledge of how science and graduate schools work in general and outside voices that were independent from the students' specific institutions. Coaches were also seen as a second opinion on matters related to professional development, funding applications, and managing negative experiences or treatment related to race, ethnicity, and gender. For example, we found that both coaches and peers were called upon for support in planning or writing grants and fellowships. Grant writing is an integral component of surviving and thriving in academic science (Dumanis et al., 2013) and is a major reason why many students move away from academic careers during the first few years of the $\mathrm{PhD}$ (Fuhrmann et al., 2011). Despite this, information and guidance on grant writing and professional development in general may still be lacking even at the postdoctoral stage (Gibbs and Griffin, 2013). As such, any intervention seeking to encourage and support PhDs in their pursuit of an academic career should incorporate significant and dedicated grant-writing guidance as well as guidance related more generally to professional development skill sets.
In terms of appraisal support, students served to validate and also normalize one another's concerns. Again, the comparatively noncompetitive environment of the Academy enabled students to be more candid than they might otherwise have been about some of their insecurities, for example, their stress over qualifying exams or doubts about whether they were good enough students. Students also benefited from discussions with other URMs - both peers and coaches. Honest and open conversations about the very real additional challenges URM students face, including feeling socially isolated or like "the only one" of a given racial or ethnic identity or background are important and even necessary. The opportunity to share challenging experiences served to validate- or normalize-URM students' lived experiences of isolation or discrimination, and may thereby have helped them to cope with the stress caused by those experiences.

As noted earlier, much of the literature on social support has tended to focus on emotional support. Thus, another important contribution of this paper is that it provides a detailed qualitative analysis of three subtypes of social support. However, a limitation of the study is that it did not seek to explore any interrelations or overlaps between the different subtypes of social support. The main purpose of the paper was to provide an empirical account on the potential benefits of coaching, using social support as an analytical lens. Future research could build on the present analysis by qualitatively looking at ways in which emotional, informational, and appraisal support interact and overlap. It has been argued, however, that there is a need to look at social support in context (Sarason and Sarason, 1990).

Another limitation of this paper is that it did not seek to explore the intersectional nature of race and gender. Although we did not systematically explore whether males or females were more likely to perceive the Academy as providing social support or different types of social support, no obvious patterns emerged in our analysis. For example, URM males and females were equally as likely to perceive their coaches or groups to be sources of emotional support. The specific coach and group were more predictive of whether or not students within the group were likely to feel they were being supported. Differences between coaches and coaching groups will be explored in a forthcoming analysis. Additionally, we did not seek to explore in depth any differences between students of different races or ethnicities (e.g., any differences between Hispanic and Black students). In the context of social support, our analysis did not uncover any differences between Hispanic and Black students in terms of whether and how they perceived the intervention to be beneficial or not. However, although the scope of particular papers often necessitates grouping (in this case, URM students), we acknowledge that such groupings can often mask a certain heterogeneity in participants' experiences and perspectives, and such heterogeneity may be revealed by additional analyses and additional analytical lenses. Heterogeneity in this study was most evident among students who expressed little need for the extra supports provided, getting all they needed from the graduate school environment and/or research mentors. Future analyses from our group will seek to explore issues of intersectionality and the uniqueness of certain populations' experiences within graduate school and in relation to science careers. For example, one of the authors (B.K.T.) has, with colleagues, recently 
examined the experiences of undergraduate Asian students negotiating their identity alongside the "model minority" stereotype (McGee et al., 2016), and we are currently looking at the experiences of Black women $\mathrm{PhD}$ students, their experiences with coaching, and whether and in what ways they benefited from it. Our future research will also seek to explore the effects of this social support on longer-term outcomes, including whether and to what extent the relationships and communities formed in the Academy during the early stages of the $\mathrm{PhD}$ are sustained through to the end of the $\mathrm{PhD}$ and beyond. It will also further explore the particular contribution of peer support in fostering persistence of URMs toward academic careers.

It is critical to recognize that, although analysis has focused on URM students, the Academy included an equal number of URM and non-URM PhD students. Many of the non-URM students experienced and benefited from all three forms of social support described here; the coaching design can benefit a high fraction of PhD students as they navigate graduate school and development as scientists. This analysis focused on URM students, because they are more likely to experience isolation and other environmental stresses associated with being only one or one of a few from a racial or ethnic group.

We continue to follow the students in the Academy through annual interviews and surveys, although none of the groups have sustained regular contact for more than a year after the last in-person meeting. This ongoing assessment will eventually determine the career outcomes of the students, whether the social support has a lasting effect, and whether they call on each other or their coaches in time of need.

In summary, our findings suggest that three main characteristics of the coaching model were seen by students to be important in fostering a supportive environment. First, group coaching is a useful addition to one-to-one coaching or mentoring as a means of building a supplementary community for students. Second, career interventions composed of diverse groups can have positive impacts on the types of conversations that are had within them. Third, having coaches and students come from different universities is important, as it allows students to talk freely and not worry about what they have said "getting back" to PIs or lab mates in their home university.

We are currently examining this coaching model in other settings, specifically in collaboration with a scientific society, initiating coaching groups the day before their annual scientific meeting. Preliminary findings indicate these groups can very quickly form strong supportive relationships with strategic bonding activities. Purposely creating groups among individuals with similar scientific interests led by an experienced coach may be an effective way to speed and strengthen identity with these critical professional networks. We also plan to see whether it is possible to create effective virtual coaching groups without an initial in-person group meeting, using more substantial video-networking methods. Virtual coaching groups will be tested in collaboration with the National Research Mentoring Network. These new approaches will determine how readily and effectively the coaching model can be "translated" into realworld settings.

Finally, it is possible that this type of coaching, through coaching groups, can be applied within institutions, provided potential coaches are given similar training to that received by the coaches in the Academy. These coaches would have to be clearly separated from any research or evaluative role with those in their groups. However, this study shows the added value of constructing diverse coaching groups with students and coaches from different institutions.

\section{ACKNOWLEDGMENTS}

This research is supported by an NIH Director's Pathfinder Award to Promote Diversity in the Scientific Workforce, "Translating Theory to Practice to Diversify the Biomedical Research Community," DP4 GM096807 (ARRA), and the following NIH grants: R01 GM085385, R01 GM085385-02S1 (ARRA), R01 NR011987, R01 GM107701, and 1R35GM118184-01. R.M. is the PI on all the above grants, and S.N.W. and B.K.T. have been funded through these grants. We thank our colleagues and other members of the Scientific Careers Research and Development Group for significant discussions throughout the course of this project: Jill Keller, PhD; Patricia Campbell, PhD; Lynn Gazley, MPH PhD; Toni Gutierrez, PhD; Beth Morrissey, MA; Sandra LaBlance, PhD; Ebony O. McGee, PhD; Robin Remich, MAT MEd; Christine Wood, PhD; Bryan Breau, BA; Steven P. Lee, $\mathrm{PhD}$; Jennifer Richardson, PhD; Michelle Naffziger-Hirsch, $\mathrm{PhD}$; Remi Jones, MA; Anne Caliendo, MSEd. Special thanks are also due to Letitia Onyango, MS, and Veronica Womack, $\mathrm{PhD}$, for their invaluable contributions to the Academy project during this study.

\section{REFERENCES}

Azmitia, M., Syed, M., \& Radmacher, K. (2013). Finding your niche: Identity and emotional support in emerging adults' adjustment to the transition to college. Journal of Research on Adolescence, 23(4), 744-761.

Bangera, G., \& Brownell, S. (2014). Course-based undergraduate research experiences can make scientific research more inclusive. CBE-Life Sciences Education, 13(4), 602-606.

Byars-Winston, A., Estrada, Y., Howard, Y., Davis, D., \& Zalapa, J. (2010). Influence of social cognitive and ethnic variables on academic goals of underrepresented students in science and engineering: A multiple-groups analysis. Journal of Counseling Psychology, 57(2), 205-218.

Cole, S., \& Barber, E. (2003). Increasing faculty diversity: The occupational choices of high-achieving minority students, Cambridge, MA: Harvard University Press

Cole, D., \& Espinoza, A. (2008). Examining the academic success of Latino students in science technology engineering and mathematics (STEM) majors. Journal of College Student Development, 49(4), 285-300.

Dumanis, S., Ullrich, L., Washington, P., \& Forcelli, P. (2013). "It's money!" Real-world grant experience through a student-run, peer-reviewed program. CBE-Life Sciences Education, 12(3), 419-428.

Dunkel-Schetter, C., \& Bennett, T. (1990). Differentiating the cognitive and behavioral aspects of social support. In Barbara, R., Sarason, I. \& Pierce, G. (Eds.), Social support: An interactional view (pp. 267-296). Oxford, UK: Wiley.

Fagen, A., \& Labov, J. (2007). Understanding interventions that encourage minorities to pursue research careers: Major questions and appropriate methods. CBE-Life Sciences Education, 6(3), 187-189.

Fuhrmann, C. N., Halme, D. G., O'Sullivan, P. S., \& Lindstaedt, B. (2011). Improving graduate education to support a branching career pipeline: Recommendations based on a survey of doctoral students in the basic biomedical sciences. CBE-Life Sciences Education, 10(3), 239-249.

Gale, N. K., Heath, G., Cameron, E., Rashid, S., \& Redwood, S. (2013). Using the framework method for the analysis of qualitative data in multi-disciplinary health research. BMC Medical Research Methodology, 31, 117.

Gazley, J. L., Remich, R., Naffziger-Hirsch, M. E., Keller, J., Campbell, P. B., \& McGee, R. (2014). Beyond preparation: Identity, cultural capital, and readiness for graduate school in the biomedical sciences. Journal of $R e-$ search in Science Teaching, 51(8), 1021-1048. 
Gibau, G. (2015). Considering student voices: Examining the experiences of underrepresented students in intervention programs. CBE-Life Sciences Education, 14(3), 3-11.

Gibbs, K., \& Griffin, K. (2013). What do I want to be with my PhD? The roles of personal values and structural dynamics in shaping the career interests of recent biomedical science PhD graduates. CBE-Life Sciences Education, 12(4), 711-723.

Gibbs, K., McGready, J., Bennett, J., \& Griffin, K. (2014). Biomedical science Ph.D. career interest patterns by race/ethnicity and gender. PLoS One, 9, https://doi.org/10.1371/journal.pone.0114736

Gibbs, K., McGready, J., \& Griffin, K. (2015). Career development among American biomedical postdocs. CBE-Life Sciences Education, 14(4), ar44.

Ginther, D. K., Schaffer, W. T., Schnell, J., Masimore, B., Liu, F., Haak, L. L., \& Kington, R. (2011). Race, ethnicity, and NIH research awards. Science, 333(6045), 1015-1019.

Glanz, K., Rimer, B., \& Lewis, F. (2002). Health behavior and health education: Theory, research, and practice, San Francisco: Jossey-Bass.

Gloria, A., Robinson, K., Hamilton, K., \& Willson, M. (1999). African American students' persistence at a predominantly white university: Influences of social support, university comfort, and self-beliefs. Journal of College Student Development, 40(3), 257.

Handelsman, J., Pfund, C., Lauffner, S. M., \& Pribbenow, C. M. (2005). Entering mentoring: A seminar to train a new generation of scientists. Madison: University of Wisconsin Press.

House, J. (1981). Work stress and social support. Boston: Addison-Wesley Educational.

House, J., Landis, K., \& Umberson, D. (1988). Social relationships and health. Science, 241(4865), 540.

Hurtado, S., Cabrera, N., Lin, M., Arellano, L., \& Espinoza, L. (2009). Diversifying science: Underrepresented student experiences in structured research programs. Research in Higher Education, 50(2), 189-214.

Hurtado, S., \& Carter, D. (1997). Effects of college transition and perceptions of the campus racial climate on Latino college students' sense of belonging. Sociology of Education, 70(4), 324-345

Hurtado, S., Eagan, K., Tran, M., Newman, C., Chang, M., \& Velasco, P. (2011). "We do science here": Underrepresented students' interactions with faculty in different college contexts. Journal of Social Issues, 67(3), 553-579.

Langford, C., Bowsher, J., Maloney, J., \& Lillis, P. (1997). Social support: A conceptual analysis. Journal of Advanced Nursing, 25(1), 95-100.

LaRocco, J., House, J., \& French, J. (1980). Social support, occupational stress, and health. Journal of Health and Social Behavior, 21(3), 202-218.

Lent, R., Brown, S., \& Hackett, G. (2000). Contextual supports and barriers to career choice: A social cognitive analysis. Journal of Counseling Psychology, 47(1), 36-49

McGee, R. (2016). Biomedical workforce diversity: The context for mentoring to develop talents and foster success within the "pipeline." AIDS and Behavior, 20, 231-237.

McGee, R., Saran, S., \& Krulwich, T. A. (2012). Diversity in the biomedical research workforce: Developing talent. Mount Sinai Journal of Medicine, 79(3), 397-411. doi: 10.1002/msj.21310

McGee, E. O., Thakore, B. K., \& LaBlance, S. (2016). The burden of being "model": Racialized experiences of Asian STEM college students. Journal of Diversity in Higher Education, 10(3), 253-270.
National Academy of Sciences. (2011). Expanding underrepresented minority participation. Washington, DC: National Academies Press.

National Institutes of Health. (2012). Draft Report of the Advisory Committee to the Director Working Group on Diversity in the Biomedical Research Workforce. https://acd.od.nih.gov/documents/reports/DiversityBiomedical ResearchWorkforceReport.pdf

Pfund, C., House, S. C., Asquith, P., Fleming, M. R., Buhr, K. A., Burnham, E. L., ... Sorkness, C. A. (2014). Training mentors of clinical and translational research scholars: A randomized controlled trial. Academic Medicine, 89(5), 774-782.

Pfund, C., House, S., Spencer, K., Asquith, P., Carney, P., Masters, K. S., ... Fleming, R. (2013). A research mentor training curriculum for clinical and translational researchers. Clinical and Translational Sciences, 6(1), 26-33.

Prunuske, A., Wilson, J., Walls, M., \& Marrin, C. B. (2016). Efforts at broadening participation in the sciences: An examination of the mentoring experiences of students from underrepresented groups. CBE-Life Sciences Education, 15(3), ar26.

Remich, R., Naffziger-Hirsch, M., Gazley, J. L., \& McGee, R. (2016). Scientific growth and identity development during a postbaccalaureate program: Results from a multisite qualitative study. CBE-Life Sciences Education, 15(3), ar25

Ritchie, J., \& Lewis, J. (2003). Qualitative research practice: A guide for social science students and researchers. London: Sage.

Sarason, B., \& Sarason, I. (1990). Social support: An interactional view. Oxford, UK: Wiley.

Sowell, R., Allum, J., \& Okahana, H. (2015). Doctoral initiative on minority attrition and completion. Washington, DC: Council of Graduate Studies.

Stewart, M. (1989). Social support: Diverse theoretical perspectives. Social Science and Medicine, 28(12), 1275-1282.

Syed, M., Azmitia, M., \& Cooper, C. (2011). Identity and academic success among underrepresented ethnic minorities: An interdisciplinary review and integration. Journal of Social Issues, 67(3), 442-468.

Thakore, B. K., Naffziger-Hirsch, M., Richardson, J., Williams, S. N., \& McGee, R. (2014). The Academy for Future Science Faculty: Randomized controlled trial of theory-driven coaching to shape development and diversity of early-career scientists. BMC Medical Education, 14, $160-171$.

Tinto, V. (1993). Leaving college: Rethinking the causes and cures of student attrition. Chicago: University of Chicago Press.

Trujillo, G., \& Tanner, K. (2014). Considering the role of affect in learning: Monitoring students' self-efficacy, sense of belonging, and science identity. CBE-Life Sciences Education, 13(1), 6-15.

Walton, G., \& Cohen, G. (2011). A brief social belonging intervention improves academic and health outcomes of minority students. Science, 331(6023), 1447-1451.

Williams, S. N., Thakore, B. K., \& McGee, R. (2016a). Coaching to augment mentoring to achieve faculty diversity: A randomized controlled trial. Academic Medicine, 91(8), 1128-1135.

Williams, S. N., Thakore, B. K., \& McGee, R. (2016b). Career coaches as a source of vicarious learning for racial and ethnic minority PhD students in the biomedical sciences: A qualitative study. PLOS ONE, 11, e0160038. doi: 10.1371/journal.pone.0160038 